\title{
Mechanisms through which diabetes mellitus influences renal cell carcinoma development and treatment: A review of the literature
}

\author{
DOMINIKA LABOCHKA ${ }^{1,2^{*}}$, BARBARA MOSZCZUK ${ }^{1,2^{*}}$, WOJCIECH KUKWA $^{3}$, \\ CEZARY SZCZYLIK ${ }^{1}$ and ANNA M. CZARNECKA ${ }^{1}$ \\ ${ }^{1}$ Department of Oncology, Military Institute of Medicine; ${ }^{2}$ Faculty of Medicine, Medical University of Warsaw; \\ ${ }^{3}$ Department of Otolaryngology, Czerniakowski Hospital, Medical University of Warsaw, Warsaw, Poland
}

Received June 14, 2016; Accepted October 6, 2016

DOI: $10.3892 /$ ijmm.2016.2776

\begin{abstract}
Renal cell carcinoma (RCC) comprises 2-3\% of all malignant tumors in adults. Many studies have established the key roles of smoking, hypertension and other components of metabolic syndrome in the occurrence of RCC. Diabetes mellitus (DM), one of the main consequences of metabolic syndrome, appears much more often in patients with RCC. The prognosis for patients suffering from both diabetes and RCC is worse than for those with kidney cancer only. Diabetes is linked to higher rate of recurrence and a greater number of distant metastases. These factors contribute to a reduction in overall survival (OS) and cause-specific survival (CSS). Diabetes can also occur as a paraneoplastic syndrome. Tyrosine kinase inhibitors (TKIs), which are agents used in the therapy of metastatic RCC, may have unexpected effects when administered to patients with diabetes. Studies and case reports have shown that they influence blood glucose levels (BGLs) in diabetic patients, sometimes causing dangerous episodes of hypoglycemia. Hyperinsulinemia and hyperglycemia can be considered independent carcinogenic factors, as they increase the amount of pro-inflammatory cytokines, reactive oxygen species and lipid peroxidation. TKIs have yet to be re-evaluated as to their safety of use in patients with diabetes.
\end{abstract}

\section{Introduction}

Renal cell carcinoma (RCC) represents $2-3 \%$ of malignant tumors in adults. The largest morbidity is noted in the developed countries, the United States and the European Union $(1,2)$.

Correspondence to: Dr Anna M. Czarnecka, Laboratory of Molecular Oncology, Department of Oncology, Military Institute of Medicine, Szaserow 128, 04-141 Warsaw, Poland

E-mail: anna.czarnecka@gmail.com

${ }^{*}$ Contributed equally

Key words: diabetes, renal cancer, tyrosine kinase inhibitor, pancreas, renal cell carcinoma, hyperinsulinemia
Over the past two decades, the incidence of RCC has steadily increased, prompting researchers to point at a modern lifestyle and resulting diseases of affluence as a possible cause. Genetic factors account for only $5 \%$ of RCC, usually as a part of hereditary, such as von Hippel-Lindau syndrome. The vast majority of renal carcinomas arises from a sporadic mutation; however, smoking, obesity and hypertension are linked to an increased risk for this malignancy (3). Histologically, three main types of RCC have been distinguished: clear cell $(80-90 \%)$, papillary (10-15\%) and chromophobe (4-5\%). Surgical treatment is considered the only curative approach. Systemic immunotherapy is offered to patients excluded from radical surgery. Cytokines (interferon- $\alpha$ ), serine-threonine mTOR kinase inhibitors (temsirolimus, everolimus), monoclonal anti-VEGF (bevacizumab) and tyrosine kinase inhibitors (TKIs) (sunitinib, sorafenib, pazopanib, axitinib) are commonly used agents (4). Kinases are enzymes capable of binding a phosphate particle to other proteins, which results in the activation or inhibition of the protein. There are two types of kinases: serine/threonine-specific and tyrosine-specific, named after the amino acids they interact with. By inhibiting the kinases, we are able to interfere with a signal transduction, which blocks cell proliferation. Over 20 TKIs are currently available; however, all the mechanisms through which they influence the human body have yet not been identified.

Diabetes mellitus (DM), a group of metabolic diseases characterized by chronic hyperglycemia, concerns approximatetly $5-7 \%$ of the adult population (5). Type 2 diabetes, associated with obesity, accounts for approximatetly $90 \%$ of cases. The underlying pathomechanism is insulin resistance caused by an excess of free fatty acids and the increased production of pro-inflammatory cytokines. Insulin resistance is initially compensated by the overproduction of insulin by the pancreas. Gradually, however, a degeneration of pancreatic $\beta$-cells takes place and diabetes develops.

Over the years, it has become clear that there is a link between RCC and diabetes, both in the incidence of the disease and in the prognosis and treatment (6). There is also a growing body of evidence indicating that immunotherapy used in metastatic RCC has significant, possibly positive effects on blood glucose levels (BGLs) in patients with diabetes. Our goal was to deliver a comprehensive literature review on the subject and to raise awareness of the phenomenon. 


\section{Data collection methods}

We researched PubMed for studies concerning our topic of interest. Retrospective and prospective studies were included, both on humans and on animals. All articles had at least an abstract written in English; translation services were used for further content.

\section{Results of the literature review}

Comorbidity: RCC and DM. The first study confirming the bond between diabetes and RCC was published by Lindblad et al in 1999 (7). Their retrospective study analyzed 153,852 Swedish patients with diabetes. The estimated incidence of RCC for this group should have been 182.4 cases; however, there were 267 cases. Clearly, diabetic patients had an increased incidence of RCC. The statistical terms used to assess this result are the standardized incidence ratio (SIR) and the standardized mortality ratio (SMR). SIR describes the ratio of the observed cases (incidence) to the expected cases (estimated prevalence), while the SMR describes the ratio of the actual number of deaths to the number expected. These two indicators prove that there is a correlation between RCC and DM in both males and females. SIR has been calculated for incidence in the female population (SIR, 1.7; 95\% CI, 1.4-2.0) and the male population (SIR, 1.3; 95\% CI, 1.1-1.6), and SMR has been calculated for mortality among women (SMR, 1.9; 95\% CI, 1.7-2.2) and men (SMR, 1.7; 95\% CI, 1.4-1.9).

In the current literature, the percentage of patients with DM and with kidney cancer ranges from 9.1\% in the Italian population (8) to as high as $25.4 \%$ among residents of Texas in the United States (9). In females, this association is more pronounced ( $31.4 \%$ comorbidity in women and $20.8 \%$ in men; $\mathrm{p}=0.01$ ) (9). Many studies have proven that diabetes is an independent risk factor for RCC (7,13-17). In a previous study, the gazard ratio (HR) or relative risk (RR), which served as an indicator, reached 1,161 (whereas the confidence indicator was 95\% CI, 1.19-2.18) (10). In another study, this rate was HR, 1.92 (95\% CI, 1.06-3.46) (11). Patients with diabetes who developed kidney cancer were older than patients without DM $(12,13)$ and more likely to have an asymptomatic course (13). The main subtype was clear cell carcinoma $(9,12)$, with a usually small tumor size $(1-5 \mathrm{~cm})(9)$. These patients were also more often afflicted with multiple diseases (13).

The prognosis for patients who developed both diseases was also investigated. A previous study on the Turkish population found, using Kaplan-Meier analysis, that there were fewer 5-year survivals in the DM group (62.9 vs. 77.7\%), $\mathrm{p}=0.1$ (12). Opinions on the impact of diabetes on mortality in RCC differ. There are sources that suggest a total lack of effect of DM on mortality (13), whereas other sources report an increased mortality in these patients (7). In another study, multivariate analysis on Japanese patients indicated the impact of diabetes on shorter survival rates, both non-cancer-related survival rates (survival unrelated to cancer) (HR, 2.22; 95\% CI, 1.06-4.64) as well as overall survival (OS) rates (HR, 1.88; 95\% CI, 1.09-13.23) (14). The study by Vavallo et al reported a shorter OS, an increased risk of recurrence and a higher mortality risk associated with kidney cancer [cause-specific survival (CSS)] (15). The meta-analysis by Chen et al suggested that DM was significantly associated with poor OS, CSS and RFS in patients with RCC (16).

The potential association of pre-existing diabetes and pre-operative HbAlc with outcomes was tested by Lee et al. Their multivariate analyses showed that diabetes was an independent predictor of disease progression (HR, 1.766; $p=0.002$ ), all-cause mortality $(\mathrm{OR}, 1.825 ; \mathrm{p}=0.001)$ and cancer-specific mortality (HR, 2.266; $\mathrm{p}=0.001$ ). Pre-operative high HbAlc predicted post-operative disease progression (HR, 2.221; $\mathrm{p}=0.023)$ (17). Diabetes also increases the risk of malignancy recurrence. Fukushima et al proved a significant difference in the 5-year relapse-free survival between patients with and without diabetes (75.3 vs. $91.9 \%, \mathrm{p}<0.001)(18)$. All these data indicate that diabetes not only affects the incidence of RCC, but also deteriorates the prognosis of patients (Fig. 1).

Obesity as a factor leading to diabetes and its role in carcinogenesis. Obesity is the most important risk factor leading to DM type 2. The greatest risk for a patient is central obesity, which is characterized by an increased amount of visceral fat. Its adipocytes secrete substances responsible for insulin resistance, e.g., free fatty acids.

The question of obesity arises in the incidence of kidney cancer. Studies have proven the link between excess body weight and an increased risk of breast cancer in post-menopausal women, endometrial and colon cancer, adenocarcinoma of the esophagus and even pancreatic cancer $(19,20)$. The role of excessive body mass in RCC was confirmed by a study on the population of the United States, where the RR rate was 1.5 (BMI, $25-30 \mathrm{~kg} / \mathrm{m}^{2}$ ) compared to 2.5 in obese subjects $\left(\mathrm{BMI}>30 \mathrm{~kg} / \mathrm{m}^{2}\right)(19)$. An increased risk resulting from a greater BMI was more pronounced in women. It is important to emphasize that obesity is a risk factor independent of blood pressure, which suggests a different mechanism of action. Obese subjects are more likely to develop clear cell subtype RCC than subjects with a normal BMI (OR, 1.48; 95\% CI, 1.19-1.84) (21,22). However, there has also been a study on the Japanese population which demonstrated that BMI did not play a statistically significant role $(p=0.991)$ in the recurrence of RCC (18).

Paraneoplastic syndromes as other manifestations of diabetes in $R C C$. Diabetes can be a rare paraneoplastic syndrome. Two such cases have been reported. The first patient, described in 1999, was a 35-year-old man, suffering from diabetes for 12 years. He was admitted to the hospital due to a sudden loss of glycemic control. The insulin demand increased from 80 units s.c. to 600 units i.v. What is more, during a physical examination, he complained of a pain on the right side, and his blood test revealed increased levels of C-reactive protein (CRP). Hematuria was discovered during a urine test. A subsequently ordered CT scan revealed a bilateral renal tumor. Following a histopathological examination, he was diagnosed with bilateral papillary carcinoma. Following a radical left-side nephrectomy and nephron-sparing surgery (NSS) on the right side, the control of diabetes returned to normal (22).

The second case was a 64-year-old patient with a history of nephrectomy due to RCC, clear cell type. Nine years after surgery, the man was admitted to the hospital with a 2-week history of polydipsia, polyuria and weight loss. Blood tests 


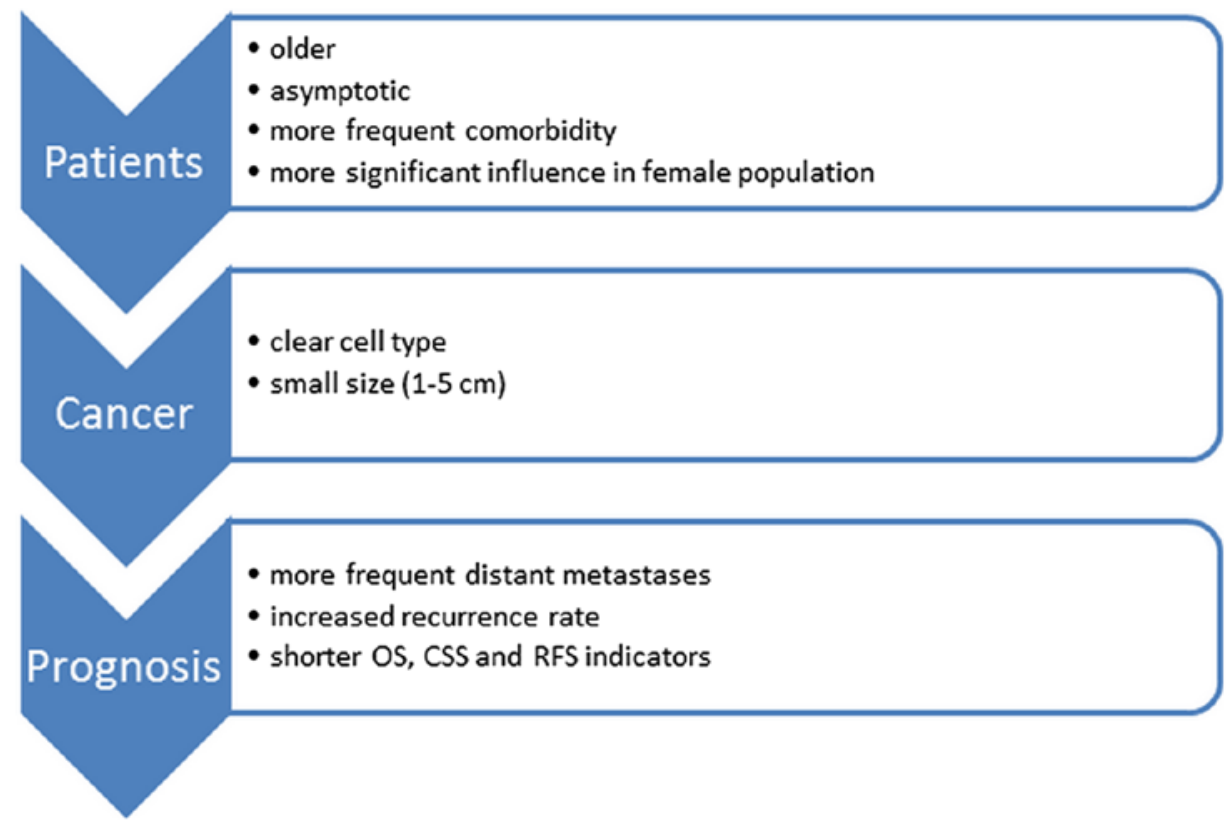

Figure 1. Clinical characteristics of coincidental renal cell carcinoma (RCC) in patients with diabetes mellitus (DM).

revealed the following levels: glucose, $662 \mathrm{mg} \%$; HbA1c, $11.5 \%$; and anti-glutamic acid decarboxylase (GAD) 28,680 U/1 (normal <9.5 U/l). The abdominal CT scan revealed progression; sunitinib treatment was ordered. Within 9 months, the dosage of insulin had been systematically reduced and finally discontinued. This state lasted at least 7 months, counting from the date of appearance. After 15 months of follow-up, the levels of anti-GAD were still elevated (23).

Treatment with TKIs in metastatic RCC and its influence on diabetic disorders. In a study conducted on mice, Louvet et al achieved the remission of type 1 diabetes in NOD mice 1 week after the initiation of therapy (24). Two years later, Agostino et al studied the average BGLs of 80 patients treated with TKIs, including 30 treated with sunitinib and 23 with sorafenib. Both groups (DM and non-DM) experienced a decrease in the average glucose level of 14 and $15 \mathrm{mg} / \mathrm{dl}$ for sunitinib and $12 \mathrm{mg} / \mathrm{dl}$ for sorafenib, respectively. Discontinuation of the treatment resulted in an increase of BGLs to the previous values associated with DM. In total, $47 \%$ of the respondents were able to stop taking their anti-glycemic agents during treatment with TKIs (25).

Improvement in glycemic control via oral anti-diabetic drugs was also described by Billemont et al. Their report analyzed the impact of sunitinib therapy on 28 patients with metastatic RCC (19 patients with DM). BGL assessment during the 4-week therapy showed that all DM patients experienced a significant, yet reversible, reduction in blood glucose (average of $1.77 \mathrm{mmol} / \mathrm{l})$. Two patients discontinued taking the oral anti-glycemic agents entirely, and five achieved BGL results defined as normal until the end of the therapy. This result was not repeated in healthy patients, and blood glucose reduction was not statistically significant $(0.17 \mathrm{mmol} / \mathrm{l})(26)$.

Improvement in glycemic control also occurred during the administration of pazopanib. A 73-year-old patient stopped taking glibenclamide due to an average drop in self-measured blood glucose of $5 \mathrm{mmol} / \mathrm{l}$ and $\mathrm{HbA} 1 \mathrm{C}$ reduction from 10.9 to $7 \%$. Weight and kidney functions were unaltered (27). A life-threatening hypoglycemia during sunitinib administration was described by Lee et al. In this case, the patient had been diagnosed with diabetes, although the episode could only be explained as a side-effect of kinase inhibitors (28).

The latest reports provide further evidence of the impact of TKIs on the glycemic state. Research carried out by Oh et al (29) revealed a significant decrease in the mean BGL in patients with diabetes. The average score before treatment was $185.2 \pm 52.8$ and $76.1 \pm 29.0 \mathrm{mg} / \mathrm{dl} 4$ weeks after treatment. After such significant changes in blood test results, $40 \%$ of the patients changed their oral dose of hypoglycemic medication or even discontinued its use. In contrary to results of the study by Agostino et al (25), patients without diabetes demonstrated only a slight downward trend in the level of glucose. Moreover, in the whole group of 48 patients, no significant changes in BMI were noted (29). In another case, among 10 patients on sorafenib therapy, four required a reduction of insulin dose (30).

Multiple case reports showing a reduction of insulin dose in patients treated with TKI have been published. A case report from 2014 described a woman with type 1 DM who underwent a pancreoduodenectomy due to a neuroendocrine tumor of the pancreas. She was administered sunitinib after metastases were discovered. Within 3 months of the treatment, the patient's need for insulin gradually diminished. This state lasted until her death due to sepsis following pneumonia 3 months later. It is worth noting that the woman was suffering from type $1 \mathrm{DM}$ for 40 years (31). A similar case was described in Korea: a 57-year-old man with DM type 2 treated with metformin and glimepiride was admitted to the hospital due to a decreased level of consciousness. He was diagnosed with severe hypoglycemia and metabolic encephalopathy. No changes in physical activity, dietary habits or present infections were noted; however, he recently began taking sunitinib (50 mg/day) due to metastatic RCC (23). 
Tyrrell and Pwint analyzed a case of a 61-year-old man with type $2 \mathrm{DM}$ who, prior to sunitinib treatment, had erratic blood sugars and $\mathrm{HbAlc}$ ranging from 55 to $79 \mathrm{mmol} / \mathrm{mol}$ in a recent year. Four months after sunitinib, his HbAlc was down to $49 \mathrm{mmol} / \mathrm{mol}$ and his insulin dose had to be reduced (32). After the sunitinib dose was reduced, his blood sugars rose slightly (from $43-48$ to $52 \mathrm{mmol} / \mathrm{mol}$ ), and this trend continued with every sunitinib dose reduction until it was stopped entirely, at which point his $\mathrm{HbAlc}$ rose to $68 \mathrm{mmol} / \mathrm{mol}$. A similar phenomenon occurred after axitinib was administered, although the follow-up period was shorter due to the patient's death.

Unfortunately, TKIs may also cause hypoglycemia. A study recently published by Polish researchers investigated the influence of sunitinib on BGLs in rabbits. In animals with DM, examined between 6 and $12 \mathrm{~h}$ after the sunitinib administration, the decrease in glucose levels ranged between 14.4 and $69.6 \%$, while healthy rabbits responded with a 15.4 to $33.6 \%$ glucose drop (33).

Severe hypoglycemia in a patient with hepatocellular carcinoma due to a possible interaction between glibenclamide and the first dose of sorafenib has been described by Holstein et al (34). As no hepatic or renal dysfunction was present, this effect was attributed to sorafenib-induced inhibition of the metabolic pathway of glibenclamide.

Another case of sunitinib inducing severe hypoglycemia was reported by Demirci et al (35). A 60-year-old man with type $2 \mathrm{DM}$ treated with glimepiride was started on sunitinib, and 2 weeks afterwards he had a hypoglycemic episode not linked to drug overdose or a change in dietary habits. Five days later, the situation repeated itself, and this time the patient required an intravenous infusion of dextrose. Over the next 2 weeks, hypoglycemia appeared less frequently, and he was discharged, but did not need to continue taking glimepiride during 6 months of follow-up.

A case of recurring episodes of severe, life-threatening hypoglycemia 3 months after the initiation of sunitinib was described by Fountas et al (36). Initially, milder episodes were corrected by an increased calorie intake; however, soon the patient required intravenous dextrose administration. Laboratory tests revealed increased plasma insulin and C-peptide levels. Sunitinib was discontinued, and there was a gradual improvement in both the frequency and severity of hypoglycemic episodes until their disappearance 1 month later.

An important study on humans has recently been published. Thijs et al (37) recruited 10 patients with metastatic RCC with an indication to start sunitinib. One patient had diabetes controlled with metformin. In the week before the treatment and 1 week after its commencement, a 120-min hyperinsulinemic euglycemic clamp was performed. The obtained mean plasma insulin concentrations were significantly higher 1 week after the sunitinib administration. As several studies $(38,39)$ have shown that the pharmacokinetics of insulin aspart are not affected by an impaired renal function, it was decided that a rise in creatinine levels in patients did not play a significant role in the achieved result, the conclusion being that sunitinib reduces insulin clearance.

Less obvious results emerge when we analyze the number of hypo- and hyperglycemic episodes in the full population of patients administered sunitinib or pazopanib, making no distinction between those with DM or without it. According to survey information provided by Pfizer, 19\% of respondents reported hypoglycemic events, whereas hyperglycemia appeared in 15\% (40). Guevremont et al rated elevated BGLs, which occur in $15 \%$ of patients, among the toxic side-effects of therapy sunitinib (41). In addition, for pazopanib, cases of both hyper- and hypoglycemia have been reported in patients with metastatic RCC (42).

Molecular background for diabetes, RCC and TKI interactions Riskfactors. There are many pathways which, when activated by diabetes, can contribute to the development of RCC. The most frequently mentioned carcinogenic factors are the following.

i) Hyperglycemia. According to the Warburg hypothesis, cancer cells prefer glycolysis over the respiratory chain in the mitochondria. In order to maintain a proper metabolism, they need an increased supply of glucose. Hyperglycemia in a diabetic can stimulate the metabolism of tumor cells. Hyperglycemia also stimulates tumor cell proliferation by increased levels of protein kinase $\mathrm{C}$ (PKC) and peroxisome proliferator-activated receptors (PPARs), which can accelerate cellular metabolism and induce proliferation (43).

ii) Hyperactivation of the protein kinase $B$ (Akt)/ mammalian target of rapamycin (mTOR) pathway. Akt regulates the majority of the cellular pathways, including those responsible for renal carcinogenesis. In a study examining cancer cells from patients suffering only from RCC and from those with both RCC and diabetes, a considerably higher activity in the second group was noted (44). Tuberin is a protein released during acute renal failure. It inhibits proliferation induced by reproductive processes. Akt kinase is responsible for the phosphorylation or the inactivation of tuberin, which activates a pathway responsible for growth, proliferation and cell traffic regulation (mTOR). The activation of mTOR kinase causes the phosphorylation of p70S6K protein. Increased concentrations of phosphorylated p70S6K were detected in patients with both DM and RCC and in patients with only DM (44). It can thus be concluded that patients with diabetes have an increased activity of Akt, which causes a reduction in the tuberin concentration and the increased activity of mTOR. All these processes affect the stimulation of the proliferation of kidney cells.

iii) Hyperinsulinemia and the insulin-like growth factor (IGF) family. Insulin promotes the synthesis and activity of IGF-1. Both insulin and IGF-1 stimulate proliferation and inhibit apoptosis. IGF acts through the IGF-1 receptor. It is a transmembrane protein of tyrosine kinase activity. Its activity is required for the transmission of a signal, which occurs through the activation of phosphatidylinositol 3-kinase (PI3K) and mitogen-activated protein kinase (MAPK) (45). It is also present in tumor cells, including RCC (46). In these cells, particularly those with increased proliferation, IGF-1R is often located in the nuclear membrane, which enables a direct transcription regulation (47). The significance of this phenomenon is disputable. Aleksic et al suggested that cells with IGF-1R located in the nuclear membrane have a higher proliferation rate and are associated with a poorer prognosis (47). However, in the study by Lkhagvadorj et $a l$, an increased expression of IGF-1R was demonstrated in RCC of a lower malignancy grade (Fuhrman grading scale); this result did not apply to cancers with higher grade tumors (48). The study by Rasmuson et al 


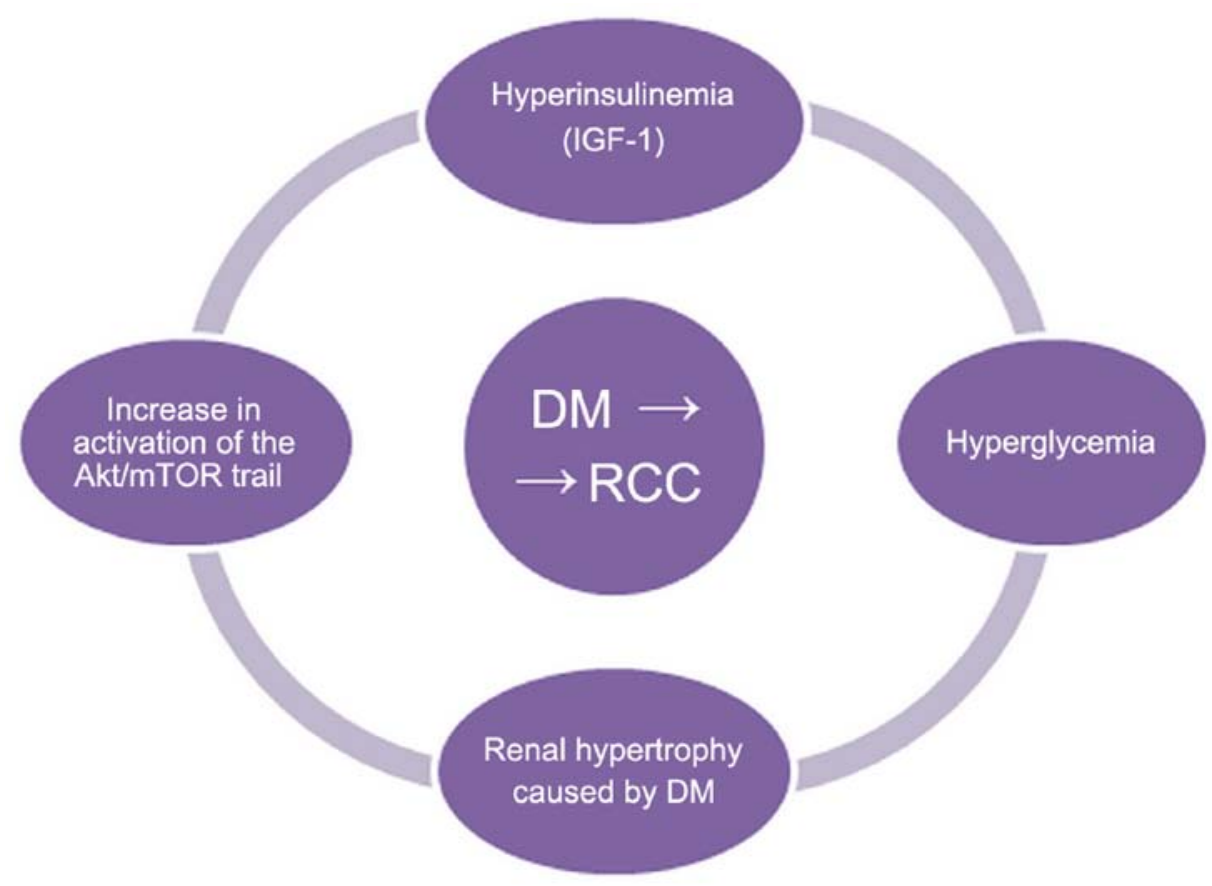

Figure 2. Potential pathways which, when activated by diabetes, can contribute to the development of renal cell carcinoma (RCC). Most frequently mentioned carcinogenic factors are: hyperglycemia, renal hypertrophy caused by diabetes mellitus (DM), increase in activation of the Akt/mTOR trail and hyperinsulinemia and insulin-like growth factor (IGF)-1 family.

showed that increased levels of IGF-1 were associated with a better prognosis $(\mathrm{p}=0.017)(49)$.

The IGF family also includes IGF-binding proteins (IGFBPs). According to the 'insulin-neoplasia' hypothesis, chronic hyperinsulinemia reduces the levels of IGFBP-1 and -2, which results in an increased bioavailability of IGF-1 (20). The most interesting binding protein is IGFBP-3. IGF-1 has a higher affinity to it than to its receptor, so that IGFBP-3 is able to reduce bioavailability and, indirectly, the activity of the growth factor. Reduced levels of IGFBP-3 are associated with a higher risk of cancer in many organs, as well as with a poorer prognosis (50) (Fig. 2).

Influence of tyrosine kinase inhibition on cells and tissues. The mechanisms through which receptor TKIs affect the metabolism of glucose have not yet been fully elucidated. There are several mechanisms through which TKIs influence glucose metabolism:

i) Inhibition of $\beta$-cell damage and increased insulin production. Hägerkvist et al hypothesized that imatinib may help to preserve $\beta$-cell mass. Under conditions of stress, Abelson tyrosine kinase (c-Abl) protein [present in large quantities in the endoplasmic reticulum (ER)] induces the apoptosis of $\beta$-cells. The protection of $\beta$-cells can be achieved by silencing $\mathrm{c}-\mathrm{Abl}$ protein with small interfering RNA (siRNA). TKIs inhibit c-Abl and c-Jun N-terminal kinase (JNK), and create a state similar to ischemic preconditioning, resulting in increased nuclear factor $(\mathrm{NF})-\kappa \mathrm{B}$ production (51).

Mokhtari et al (52) proved that imatinib activates NF- $\kappa \mathrm{B}$, which has an anti-apoptotic effect. Additionally, a decrease in the sensitivity of pancreatic cells to cytokines was noted. This could reduce the amount of amyloid formation, alleviating its unfavorable effect on pancreatic islets' performance $(52,53)$. Ono et al (54) suggested that TKIs may increase insulin production by acting against an SRC-kinase family responsible for the reduction of insulin secretion.

ii) Influence on adipose tissue macrophages. It has been proven that excessive adipose tissue is a location of a mild but chronic inflammation, which causes an increase in systemic insulin resistance (55). Up to $40 \%$ of the cells infiltrating the adipose tissue in obese mice and humans are macrophages (56). They can be divided into two subpopulations: M1 and M2 macrophages. M1 macrophages secrete cytokines, such as tumor necrosis factor (TNF) $\alpha$, interleukin (IL)- 6 and inducible nitric oxide synthase (iNOS); M2 macrophages reduce inflammation by producing IL-4 and IL-10 (57). In obese subjects, the balance between these two groups is shifted toward the M1 phenotype (58). Prada et al demonstrated that the administration of TKIs decreased the amount of circulating IL-6, TNF $\alpha$ and iNOS, which suggested that the drug had shifted the balance between macrophage subpopulations from M1 to M2 (59) (Fig. 3).

iii) Influence on insulin sensitivity and ER stress. It has also been suggested that imatinib improves insulin sensitivity (60). This could be due to a decrease in ER stress. In the study by Han et al, imatinib was administered to mice with DM type 2 for 4 weeks. Afterwards, an improvement in fasting glucose levels and glucose tolerance was noted. The levels of markers of ER stress, such as phospho-ERK or phospho-eIF2- $\alpha$ decreased. The experiment was repeated on liver cancer cells, yielding a similar result. Reduced ER stress was also accompanied by a decrease in JNK activity and insulin receptor substrate-1 (IRS-1) phosphorylation (61). Hägerkvist et al demonstrated that the administration of a TKI (PD153035 or imatinib) reduced the phosphorylation of an insulin receptor associated with insulin resistance (60). However, in the study conducted by Thijs et al, this effect was not confirmed (37) (Fig. 4). 


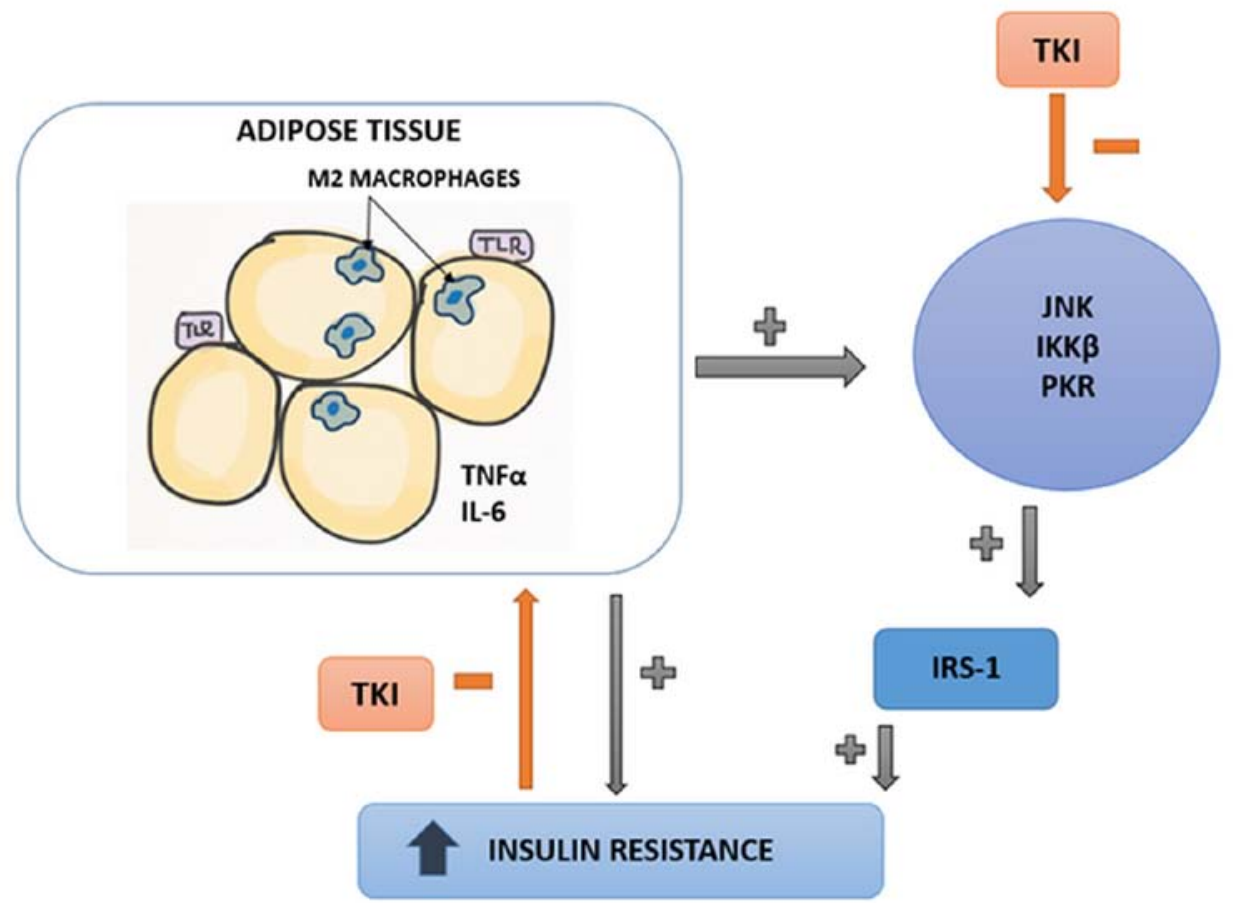

Figure 3. Influence of tyrosine kinase inhibitors (TKIs) on insulin resistance. Adipose tissue is infiltrated with M2 macrophages, promoting a constant inflammatory state [inflammatory cytokines interleukin (IL)- 6 and tumor necrosis factor (TNF) $\alpha$ ]. Inflammation promotes insulin resistance. Adipocytes express Toll-like receptor 4 (TLR4), which activates a variety of kinases, such as c-Jun N-terminal kinase (JNK), IKB kinase (IKK) and protein kinase R (PKR). Increased levels of these kinases are markers of endoplasmic reticulum stress, linked with the exhaustion of $\beta$-cells in the pancreas. Insulin receptor substrate-1 (IRS-1) activation meliorates insulin sensitivity, thus promoting diabetes. TKIs are hypothesized to hold back the conversion of M1 macrophages to the M2 type, which decreases TNFo production (anti-inflammatory effect). They also inhibit the JNK pathway, improving tissue sensitivity to insulin (decrease in IRS-1).

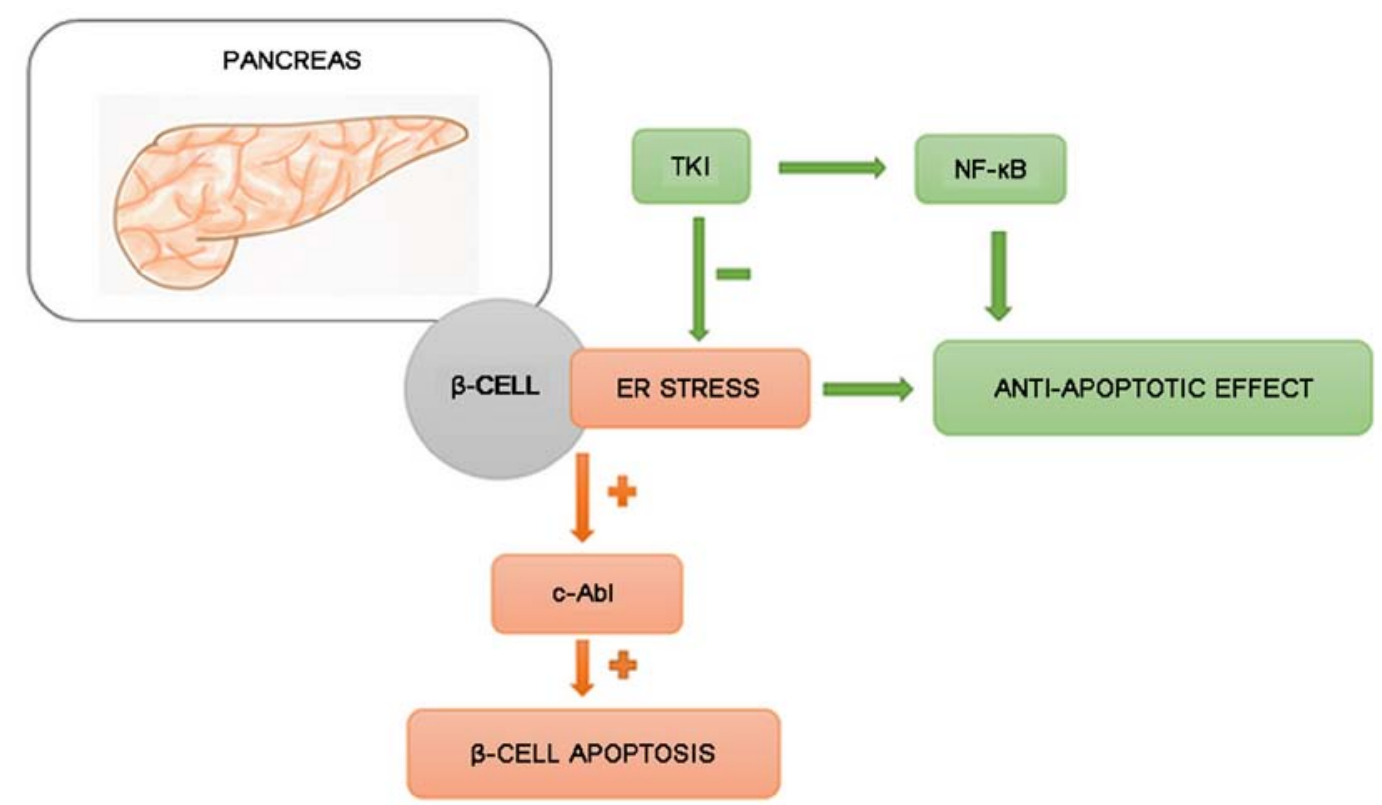

Figure 4. Anti-apoptotic effect of tyrosine kinase inhibitors (TKIs). Endoplasmic reticulum (ER) stress results in $\beta$-cell apoptosis. By reducing ER stress and promoting nuclear factor $(\mathrm{NK})$ - $\mathrm{\kappa B}$ production, TKIs promote the survival of $\beta$-cells.

\section{Discussion}

Multiple studies claim that diabetes is an independent risk factor for non-hereditary kidney cancer development and its accelerated progression (7-9). The co-occurrence of both diseases is more common in elderly patients and in women. Patients affected often have an asymptotic course and more comorbidities (10-13). Kidney cancer in diabetic patients is usually of the clear cell 
subtype with a small tumor size $(1-5 \mathrm{~cm})(14)$. The prognosis is worse than for patients suffering from kidney cancer alone. This is due to a higher rate of recurrence and a greater number of distant metastases. All these factors contribute to a reduction in survival rates, both OS and CSS. Diabetes can also occur as a paraneoplastic syndrome, thus contributing to an early diagnosis of RCC (15-24).

Reasons for severe hypoglycemia episodes and alterations in BGLs in patients treated with TKIs remain disputable. The first and most obvious explanation that comes to mind is that body mass and dietary habits change due to the disease itself. Weight loss could contribute to a decrease in insulin resistance. However, in the study by Oh et al (29), BMI reduction was very insignificant, ranging from 0.68 in diabetic to 0.25 in non-diabetic patients. Other authors, when struggling to explain numerous hypoglycemic effects, exclude all likely causes, such as drug overdose, changes in dietary habits, insulin-producing tumors or effects of corticosteroids. Moderate (grade 2) anorexia related to sunitinib treatment has been reported in $6 \%$ of patients; however, severe or life-threatening (grades 3 and 4) effects were not present at all (62). Sorafenib resulted in a decreased appetite in only $2.9 \%$ of patients in a large international study (63). In a study published in 2009, Mokhtari and Welsh suggested that trials should be conducted to verify the following hypotheses: i) TKIs prevent the destruction of $\beta$-cells in patients with recently developed type 1 diabetes; ii) TKIs inhibit inflammatory and autoimmune processes in pre-diabetic patients so that the precipitation of type 1 diabetes is delayed/prevented; and iii) TKIs improve $\beta$-cell function and insulin sensitivity in late decompensated stages of DM type 2 so that insulin therapy is no longer necessary (64). The authors of this study are aware that carrying out such trials on real-life patients can be ethically disturbing; therefore, we emphasize that large-scale animal studies should precede those on humans. Confirmation of the inhibitory effects of TKIs on the development of diabetes may result in the discovery of novel treatment methods for DM, and disproving this hypothesis would finally confirm the safety of TKIs for diabetic patients in oncological treatment.

In conclusion, the potential pathomechanisms leading to the development of kidney cancer in patients with DM remain unexplained. The most important are probably the following: chronic hyperglycemia, renal hypertrophy, Akt/mTOR trail hyperactivation and hyperinsulinemia. The role of insulin and the IGF-1 family is perhaps the most promising object of future investigation. The stimulation of cell proliferation by insulin and IGF-1 and the direct impact on transcription by the presence of IGF-1R in the cell membrane suggest that this agent is of the greatest importance in the development of RCC.

In this analysis, we wanted to draw attention to the cellular pathways leading to carcinogenesis and to potential targets for novel anticancer therapies, such as blocking the activity of IGF-1R or increasing the activity of IGFBP-3. As for the hypoglycemic effects of TKIs, we are aware that retrospective analysis on small groups of patients and relatively few animal studies are not sufficient to draw general conclusions. However, with the growing incidence of both diabetes and various oncological conditions in developed countries, we believe it is necessary to expand our knowledge on the pleiotropic impact of TKIs on the human body.

\section{Acknowledgements}

This study was supported by the National Science Centre (NCN) grant no. UMO-2012/05/D/NZ5/01844 and WIM intramural grant no. 1/8863 (355).

\section{References}

1. European Network of Cancer Registries. Eurocim version 4.0. European incidence database V2.3, 730 entity dictionary, Lyon, 2001.

2. Ferlay J, Steliarova-Foucher E, Lortet-Tieulent J, Rosso S, Coebergh JW, Comber H, Forman D and Bray F: Cancer incidence and mortality patterns in Europe: estimates for 40 countries in 2012. Eur J Cancer 49: 1374-1403, 2013.

3. Chow WH, Dong LM and Devesa S: Epidemiology and risk factors for kidney cancer. Nat Rev Urol 7: 245-257, 2010.

4. Ljungberg B, Bensalah K, Canfield S, Dabestani S, Hofmann F, Hora M, Kuczyk MA, Lam T, Marconi L, Merseburger AS, et al: EAU guidelines on renal cell carcinoma: 2014 update. Eur Urol 67: 913-924, 2015.

5. Adeghate E, Schattner P and Dunn E: An update on the etiology and epidemiology of diabetes mellitus. Ann NY Acad Sci 1084: $1-29,2006$

6. Moyad MA: Review of potential risk factors for kidney (renal cell) cancer. Semin Urol Oncol 19: 280-293, 2001.

7. Lindblad P, Chow WH, Chan J, Bergström A, Wolk A, Gridley G, McLaughlin JK, Nyrén O and Adami HO: The role of diabetes mellitus in the aetiology of renal cell cancer. Diabetologia 42: 107-112, 1999.

8. Zucchetto A, Dal Maso L, Tavani A, Montella M, Ramazzotti V, Talamini R, Canzonieri V, Garbeglio A, Negri E, Franceschi S and La Vecchia C: History of treated hypertension and diabetes mellitus and risk of renal cell cancer. Ann Oncol 18: 596-600, 2007.

9. Habib SL, Prihoda TJ, Luna M and Werner SA: Diabetes and risk of renal cell carcinoma. J Cancer 3: 42-48, 2012.

10. Joh HK, Willett WC and Cho E: Type 2 diabetes and the risk of renal cell cancer in women. Diabetes Care 34: 1552-1556, 2011.

11. Inoue M, Iwasaki M, Otani T, Sasazuki S, Noda M and Tsugane S: Diabetes mellitus and the risk of cancer: Results from a large-scale population-based cohort study in Japan. Arch Intern Med 166: 1871-1877, 2006.

12. Süier E, Oztürk E, Gülpınar O, Kayış A and Baltacı S: Effect of type 2 diabetes mellitus on prognosis of nonmetastatic renal cell cancer. Korean J Urol 54: 499-503, 2013.

13. Antonelli A, Arrighi N, Corti S, Zanotelli T, Cozzoli A, Cosciani Cunico S and Simeone C: Pre-existing type-2 diabetes is not an adverse prognostic factor in patients with renal cell carcinoma: A single-center retrospective study. Urol Oncol 31: 1310-1315, 2013.

14. Lee S, Hong SK, Kwak C, Kim HH and Lee SE: Prognostic significance of diabetes mellitus in localized renal cell carcinoma. Jpn J Clin Oncol 42: 318-324, 2012.

15. Vavallo A, Simone S, Lucarelli G, Rutigliano M, Galleggiante V, Grandaliano G, Gesualdo L, Campagna M, Cariello M, Ranieri E, et al: Pre-existing type 2 diabetes mellitus is an independent risk factor for mortality and progression in patients with renal cell carcinoma. Medicine (Baltimore) 93: e183, 2014.

16. Chen L, Li H, Gu L, Ma X, Li X, Gao Y, Zhang Y, Shen D, Fan Y, Wang B, et al: The impact of diabetes mellitus on renal cell carcinoma prognosis: A meta-analysis of cohort studies. Medicine (Baltimore) 94: e1055, 2015.

17. Lee H, Kwak C, Kim HH, Byun SS, Lee SE and Hong SK: Diabetes mellitus as an independent predictor of survival of patients surgically treated for renal cell carcinoma: A propensity score matching study. J Urol 194: 1554-1560, 2015.

18. Fukushima H, Masuda H, Yokoyama M, Tatokoro M, Yoshida S, Ishioka J, Matsuoka Y, Numao N, Koga F, Saito K, et al: Diabetes mellitus with obesity is a predictor of recurrence in patients with non-metastatic renal cell carcinoma. Jpn J Clin Oncol 43: 740-746, 2013.

19. Calle EE and Kaaks R: Overweight, obesity and cancer: Epidemiological evidence and proposed mechanisms. Nat Rev Cancer 4: 579-591, 2004.

20. Renehan AG, Roberts DL and Dive C: Obesity and cancer: Pathophysiological and biological mechanisms. Arch Physiol Biochem 114: 71-83, 2008.

21. Lowrance WT, Thompson RH, Yee DS, Kaag M, Donat SM and Russo P: Obesity is associated with a higher risk of clear-cell renal cell carcinoma than with other histologies. BJU Int 105: 16-20, 2010 . 
22. Callewaert PR, Van Poppel H, Vanderschueren D and Baert L: Uncontrollable diabetes mellitus: A rare paraneoplastic manifestation of renal cell carcinoma. Nephrol Dial Transplant 14: 2263-2264, 1999.

23. Cho M, Shim H and Park MR: Hypoglycemic coma in a patient with metastatic renal cell carcinoma treated with sunitinib. Korean J Med 87: 501-504, 2014.

24. Louvet C, Szot GL, Lang J, Lee MR, Martinier N, Bollag G, Zhu S, Weiss A and Bluestone JA: Tyrosine kinase inhibitors reverse type 1 diabetes in nonobese diabetic mice. Proc Natl Acad Sci USA 105: 18895-18900, 2008

25. Agostino NM, Chinchilli VM, Lynch CJ, Koszyk-Szewczyk A, Gingrich R, Sivik J and Drabick JJ: Effect of the tyrosine kinase inhibitors (sunitinib, sorafenib, dasatinib, and imatinib) on blood glucose levels in diabetic and nondiabetic patients in general clinical practice. J Oncol Pharm Pract 17: 197-202, 2011.

26. Billemont B, Medioni J, Taillade L, Helley D, Meric JB, Rixe O and Oudard S: Blood glucose levels in patients with metastatic renal cell carcinoma treated with sunitinib. Br J Cancer 99: 1380-1382, 2008.

27. Böhm S, Hess D, Gillessen S and Brändle M: Improved glycemic control with the multi-receptor tyrosine kinase inhibitor pazopanib. Diabetes Care 33: e82, 2010.

28. Lee Y, Jung HS, Choi HJ, Kim MJ, Kim TM, Park KS and Kim SY: Life-threatening hypoglycemia induced by a tyrosine kinase inhibitor in a patient with neuroendocrine tumor: A case report. Diabetes Res Clin Pract 93: e68-e70, 2011.

29. Oh JJ, Hong SK, Joo YM, Lee BK, Min SH, Lee S, Byun SS and Lee SE: Impact of sunitinib treatment on blood glucose levels in patients with metastatic renal cell carcinoma. Jpn J Clin Oncol 42: 314-317, 2012.

30. Imarisio I, Paglino C, Ganini C, Magnani L, Caccialanza R and Porta C: The effect of sorafenib treatment on the diabetic status of patients with renal cell or hepatocellular carcinoma. Future Oncol 8: 1051-1057, 2012.

31. Huda MSB, Amiel SA, Ross P and Aylwin SJ: Tyrosine kinase inhibitor sunitinib allows insulin independence in long-standing type 1 diabetes. Diabetes Care 37: e87-e88, 2014.

32. Tyrrell HE and Pwint T: Sunitinib and improved diabetes control. BMJ Case Rep 2014: 2014.

33. Szałek E, Karbownik A, Sobańska K, Grabowski T, Połom W, Lewandowska M, Wolc A, Matuszewski M and Grześkowiak E: The pharmacokinetics and hypoglycaemic effect of sunitinib in the diabetic rabbits. Pharmacol Rep 66: 892-896, 2014.

34. Holstein A, Kovacs P and Beil W: Severe hypoglycemia due to possible interaction between glibenclamide and sorafenib in a patient with hepatocellular carcinoma. Curr Drug Saf 8: 148-152, 2013.

35. Demirci A, Bal O, Durnali A, Ekinci AŞ, Eşbah O, Alkiş N and Oksüzoğlu B: Sunitinib-induced severe hypoglycemia in a diabetic patient. J Oncol Pharm Pract 20: 469-472, 2014.

36. Fountas A, Tigas S, Giotaki Z, Petrakis D, Pentheroudakis G and Tsatsoulis A: Severe resistant hypoglycemia in a patient with a pancreatic neuroendocrine tumor on sunitinib treatment. Hormones (Athens) 14: 438-441, 2015.

37. Thijs AM, Tack CJ, van der Graaf WT, Rongen GA and van Herpen CM: The early effect of sunitinib on insulin clearance in patients with metastatic renal cell carcinoma. Br J Clin Pharmacol 81: 768-772, 2016.

38. Holmes G, Galitz L, Hu P and Lyness W: Pharmacokinetics of insulin aspart in obesity, renal impairment or hepatic impairment. Br J Clin Pharmacol 60: 469-476, 2005.

39. Kulozik $\mathrm{F}$ and Hasslacher $\mathrm{C}$ : Insulin requirements in patients with diabetes and declining kidney function: differences between insulin analogues and human insulin? Ther Adv Endocrinol Metab 4: 113-121, 2013.

40. Lodish MB and Stratakis CA: Endocrine side effects of broad-acting kinase inhibitors. Endocr Relat Cancer 17: R233-R244, 2010.

41. Guevremont C, Alasker A and Karakiewicz PI: Management of sorafenib, sunitinib, and temsirolimus toxicity in metastatic renal cell carcinoma. Curr Opin Support Palliat Care 3: 170-179, 2009

42. Sternberg CN, Davis ID, Mardiak J, Szczylik C, Lee E, Wagstaff J, Barrios CH, Salman P, Gladkov OA, Kavina A, et al: Pazopanib in locally advanced or metastatic renal cell carcinoma: Results of a randomized phase III trial. J Clin Oncol 28: 1061-1068, 2010.

43. Ryu TY, Park J and Scherer PE: Hyperglycemia as a risk factor for cancer progression. Diabetes Metab J 38: 330-336, 2014.
44. Habib SL and Liang S: Hyperactivation of Akt/mTOR and deficiency in tuberin increased the oxidative DNA damage in kidney cancer patients with diabetes. Oncotarget 5: 2542-2550, 2014.

45. Chitnis MM, Yuen JS, Protheroe AS, Pollak M and Macaulay VM: The type 1 insulin-like growth factor receptor pathway. Clin Cancer Res 14: 6364-6370, 2008.

46. Ouban A, Muraca P, Yeatman T and Coppola D: Expression and distribution of insulin-like growth factor-1 receptor in human carcinomas. Hum Pathol 34: 803-808, 2003.

47. Aleksic T, Chitnis MM, Perestenko OV, Gao S, Thomas PH, Turner GD, Protheroe AS, Howarth M and Macaulay VM: Type 1 insulin-like growth factor receptor translocates to the nucleus of human tumor cells. Cancer Res 70: 6412-6419, 2010.

48. Lkhagvadorj S, Oh SS, Lee MR, Jung JH, Chung HC, Cha SK and Eom M: Insulin receptor expression in clear cell renal cell carcinoma and its relation to prognosis. Yonsei Med J 55: 861-870, 2014.

49. Rasmuson T, Grankvist K, Jacobsen J, Olsson T and Ljungberg B: Serum insulin-like growth factor-1 is an independent predictor of prognosis in patients with renal cell carcinoma. Acta Oncol 43: 744-748, 2004.

50. Samani AA, Yakar S, LeRoith D and Brodt P: The role of the IGF system in cancer growth and metastasis: Overview and recent insights. Endocr Rev 28: 20-47, 2007.

51. Hägerkvist R, Makeeva N, Elliman S and Welsh N: Imatinib mesylate (Gleevec) protects against streptozotocin-induced diabetes and islet cell death in vitro. Cell Biol Int 30: 1013-1017, 2006.

52. Mokhtari D, Li T, Lu T and Welsh N: Effects of Imatinib Mesylate (Gleevec) on human islet NF-kappaB activation and chemokine production in vitro. PLoS One 6: e24831, 2011.

53. Welsh N: Does the small tyrosine kinase inhibitor Imatinib mesylate counteract diabetes by affecting pancreatic islet amyloidosis and fibrosis? Expert Opin Investig Drugs 21: 1743-1750, 2012

54. Ono K, Suzushima H, Watanabe Y, Kikukawa Y, Shimomura T, Furukawa N, Kawaguchi T and Araki E: Rapid Amelioration of hyperglycemia facilitated by dasatinib in a chronic myeloid leukemia patient with type 2 diabetes mellitus. Intern Med 51: 2763-2766, 2012

55. Xu H, Barnes GT, Yang Q, Tan G, Yang D, Chou CJ, Sole J, Nichols A, Ross JS, Tartaglia LA and Chen H: Chronic inflammation in fat plays a crucial role in the development of obesity-related insulin resistance. J Clin Invest 112: 1821-1830, 2003.

56. Weisberg SP, McCann D, Desai M, Rosenbaum M, Leibel RL and Ferrante AW Jr: Obesity is associated with macrophage accumulation in adipose tissue. J Clin Invest 112: 1796-1808, 2003.

57. Gordon S and Martinez FO: Alternative activation of macrophages: Mechanism and functions. Immunity 32: 593-604, 2010.

58. Gregor MF and Hotamisligil GS: Inflammatory mechanisms in obesity. Annu Rev Immunol 29: 415-445, 2011.

59. Prada PO, Ropelle ER, Mourão RH, de Souza CT, Pauli JR, Cintra DE, Schenka A, Rocco SA, Rittner R, Franchini KG, et al: EGFR tyrosine kinase inhibitor (PD153035) improves glucose tolerance and insulin action in high-fat diet-fed mice. Diabetes 58: 2910-2919, 2009.

60. Hägerkvist R, Jansson L and Welsh N: Imatinib mesylate improves insulin sensitivity and glucose disposal rates in rats fed a high-fat diet. Clin Sci (Lond) 114: 65-71, 2008.

61. Han MS, Chung KW, Cheon HG, Rhee SD, Yoon CH, Lee MK, Kim KW and Lee MS: Imatinib mesylate reduces endoplasmic reticulum stress and induces remission of diabetes in $\mathrm{db} / \mathrm{db}$ mice. Diabetes 58: 329-336, 2009.

62. Motzer RJ, Michaelson MD, Redman BG, Hudes GR, Wilding G, Figlin RA, Ginsberg MS, Kim ST, Baum CM, DePrimo SE, et al: Activity of SU11248, a multitargeted inhibitor of vascular endothelial growth factor receptor and platelet-derived growth factor receptor, in patients with metastatic renal cell carcinoma. J Clin Oncol 24: 16-24, 2006.

63. Jäger D, Ma JH, Mardiak J, Ye DW, Korbenfeld E, Zemanova M, Ahn H, Guo J, Leonhartsberger N, Stauch K, et al: Sorafenib treatment of advanced renal cell carcinoma patients in daily practice: The large international PREDICT study. Clin Genitourin Cancer 13: 156-64.e1, 2015.

64. Mokhtari D and Welsh N: Potential utility of small tyrosine kinase inhibitors in the treatment of diabetes. Clin Sci (Lond) 118: 241-247, 2009. 